\title{
Speech behaviour in talk-shows on the basis of critical analysis of Oprah Winfrey's speech portrait
}

\author{
Lidianna Chunakhova ${ }^{1}$, Anastasia Vnukovskaya $^{2}$, and Valeria Nesterova $^{3}$ \\ ${ }^{1}$ Don State Technical University, Gagarin Sq., 1, Rostov-on-Don, Russian Federation \\ ${ }^{2}$ Rostov Law Institute of the Ministry of Internal Affairs of Russia, Eremenko Str., 83, Rostov-on- \\ Don, Russian Federation \\ ${ }^{3}$ Ural Law Institute of the Ministry of Internal Affairs of Russia, Korepin Str., 66, Ekaterinburg, \\ Russian Federation
}

\begin{abstract}
The success of a TV personality, both in the social and professional sphere, depends on the speed and effectiveness of his thinking, creative behavior in unexpected and unpredictable situations. The ability to quickly navigate various communication situations, find a successful path contributes to success. Knowledge about speech behaviour, speech impact, as well as the ability to use speech strategies and tactics can help achieve definite goals and increase communication efficiency. The study of speech behaviour of Oprah Winfrey has been carried out within the framework of hidden pragmalinguistics. The conducted research contributes to the development of a methodology for diagnosing the personality qualities of a speaker by his speech, to the theory of studying stereotypical speech behavior of professional groups.
\end{abstract}

\section{Introduction}

Speech behaviour develops throughout the whole lifetime of an individual, been determined by his or her social characteristics, including the birthplace, the place where the person grows, education, age, gender, profession and many other relevant factors [1]. Meanwhile, speech activity is the activity of the sender of the text on the motivated, targeted choice of language means in specific conditions of the speech act with the aim of the optimal impact on the recipient. Speech behaviour directly traces the linguistic personality [2], which has both individual and social experience of intercourse and interaction with different representatives of a particular social group.

Speech behaviour of a given person depends on many factors. Speech activity is a motivated and focused choice of lingual units aimed at achieving a specific goal successful impact on the opponent. Speech strategy is the total of all speech actions, while speech actions are realized through specific tactics that contribute to the implementation of this strategy [3]. The main tool for implementing speech tactics is the communicative

\footnotetext{
* Corresponding author: dilana@,bk.ru
} 
course, which is characterized by the urge to achieve a certain communicative goal and successful communication. The speech strategy is primarily chosen by the speaker depending on the circumstances and the situation in which the communication takes place. In the process of communication, the strategy is implemented by using a set of speech tactics, which are determined by the individual choice of certain speech patterns and lingual units.

\section{Problem statement}

American TV presenter, actress and producer, Oprah Winfrey is the most influential woman in America. She is well-known for her famous talk show "Oprah Winfrey», which has become popular not only in the United States, but all over the world. She is admired by every woman; she is a real role model to follow. She achieved her success thanks to arduous and strenuous work in all areas. She has survived a number of obstacles - she had to face poverty, racism, sexual violence, and lifelong overweight. Today, the Oprah Winfrey Show is the highest rated talk show in television history. Since appearing in syndication in 1986, the Oprah Winfrey Show has remained the number one talk show for 10 consecutive seasons, earning 25 Emmy Awards.

According to American news and World Report, Oprah has an ability called «the Oprah Effect». What makes her popular is not only her talent as an artist, but also her talent as a good presenter [4]. She has all the qualities necessary for that. Firstly, she always explores and prepares the topic the day before the show. This training and research allows her to answer any controversial or provocative questions. And she is always able to support both sides of the topic and never leaves the audience unsatisfied or misleading. Secondly, she has high self-esteem. She's always confident and full of energy. Thirdly, she shows respect for the audience and guests in the studio by listening to their opinions. She maintains the direct eye contact and gives rational answers throughout the on-the-air time. Other characteristics that make her a good leader are the use of appropriate words, phrases, word combinations, etc. She knows which words are suitable for various races and ages. For example, she knows some words that are suitable for African Americans, but a taboo for white Americans [5]. She always speaks at a good pace and makes sure that the audience comprehend her thoughts. With the characteristics mentioned above and hard work, Oprah became the best TV presenter of an American talk show.

\section{Research questions}

The research carried out in this paper intended to answer the following questions:

3.1 What are the phonetic peculiarities of Oprah Winfrey's speech behaviour?

3.2 What are the lexical features characteristic of Oprah Winfrey's speech behaviour?

3.3. What are the most common syntactic structures used as manipulative tools in Oprah's interviews?

\section{Purpose of the study}

The purpose of this research is to eliminate, classify and describe phonetic expressive means, lexical devices and syntactic patterns used in the speech of Oprah Winfrey as a popular talk show presenter with the aim of investigating the hidden pragmatic effect that her speech behaviour produces on public consciousness. 


\section{Research method}

An important role in the study of speech portraiture is occupied by the term speech behaviour. Speech behaviour is one-way, it displays those characteristic features that are inherent in one of the participants of the communication process - the speaker or listener [6].

Speech behaviour is directly related to the term speech activity. Speech activities include the conscious, deliberate choice of lingual and speech units necessary for achieving the goal and motivation of the speaker. Thereby, this is an activity carried out by a person consciously [7]. The result of speech activity is the very thought that the speaker wants to convey and the text, while the result of speech behaviour is direct interaction between people and emotions that will be caused by one or another interlocutor's speech behaviour.

Speech behaviour is a certain image of a person that consists of a specific set of speech patterns according to his or her experience and the circumstances in which the process of communication takes place. That is, both linguistic and extralinguistic factors are inseparably connected in speech behaviour. The very structure of speech behaviour consists of verbal and non-verbal features. Verbal behaviour is characterized by a set of verbal reactions, that is, how a person asks questions, how he disposes of himself in relation to the interlocutor. Non-verbal behaviour is a set of kinetic means, including facial expressions, gestures, gaze, pose and gait. These are also prosodic means (pitch level, timbre of voice, strength of stress), extralinguistic (pauses, laughter, crying, coughing, sighs), tactile (handshakes, kisses, touches expressed in the form of patting on the shoulder or back) and proxemic means (spatial organization of communication).

Speech behaviour depends on the position of a person in society, on his profession. A journalist or a presenter will skillfully use his speech features, ask the right questions and competently regulate communication to achieve success. However, the speech portrait is associated not only with the social status of the person, but also with the individual inherent features [8].

Human speech abounds in various syntactic means, allowing not only to enrich it, but also to express thoughts directly as well as hiding the true intention from the interlocutors. Scientists call the actions that a person commits by leading his opponent to commit certain actions or to mislead him as speech strategies and tactics.

The study of speech strategies and tactics is quite relevant at present, since they allow to recognize the speech behaviour of a person in a certain situation. The choice of strategy is determined by the situation in which communication takes place, and by the purpose or motivation of an individual.

The materials analyzed in the article were the scripts of 12 Oprah Winfrey's talk shows. The texts were divided into small syntactic groups (SSG). Total of 645 SSG were analyzed. The methods of research are determined by the specifics of the material, as well as the goals and objectives of this work. We use the statistically representative sampling, observation method (viewing talk show releases) and the method of objective pragmalinguistic analysis with the elements of modified content analysis.

\section{Findings}

To compile a characteristic, it is necessary to consider and analyze phonetic, lexical and syntactic features of the speech of the text sender. Thus, the research opened with considering the phonetic features of Oprah Winfrey's speech. Phonetic tools play an important role in creating an integral image of speech text, in expressing its thematic development. Phonetic expressive means and stylistic devices can include intonation, rhyme and rhythm, onomatopoeia, alliteration, assonance, euphony, etc. 
Euphony involves combination of lovely, melodic sounds convenient for pronunciation and hearing. Consider such words and expressions: "Good evening!», "Ladies and Gentlemen», "Let me ask you», "Tonight». These phrases include a combination of sonorants and vowels that produce pleasant acoustic effect. Alliteration is the next technique that gives Oprah's statements special expressiveness:

(1) «And defied definition for years» [9]

Onomatopoeia is another phonetic device in which certain words due to their sound combination call associations to a depicted phenomenon, action or emotion since their sounds resemble the actions they call: "Blah-blah», "Sh...», "Wow», etc.

Having analyzed the set of phonetic expressive means found in Oprah Winfrey's utterances, one can conclude that the TV presenter is quite competent in expressing her thoughts skillfully, clearly and graciously, which indicates that Oprah is a highly intelligent person.

Oprah also uses a large set of lexical expressive means [10]. She does not use standard phrases or cliches, her speech is elaborate and eloquent. A distinctive feature of the individual style of Oprah Winfrey is focusing on the uniqueness of the people invited to her show [11]. Presenting her quests, she tells a story using adjectives in the superlative degree, as if trying to hyperbolize the image of a person and deliberately exaggerate the importance of a particular event in his or her life:

(2) «Good evening, I am Oprah Winfrey, bringing you a world exclusive interview with the most exclusive superstar in the history of music, Michael Jackson» [9]

(3) "What's been the hardest thing for you» [9]

In most cases, she uses words and phrases with positive connotations and emotive colouring. Oprah Winfrey quite often resorts to metaphors as decorative devices:

(4) "When you become an icon of an industry» [9]

(5) «Where just inside is the man who has broken every possible musical record» [54] The skillful use of metaphor [12] signals that the speaker possesses figurative thinking and vision of similarities and analogies in figurative structures.

The next expressive device is metonymy. Metonymy is the transfer of a name from one subject or phenomenon to another on the basis of contiguity, proximity, spatial and temporal connection. The replacement word is used in a figurative meaning:

(6) "And the car is waiting outside to take right now to the airport» [13]

Simile is a stylistic device which effect is realized by comparing one object with another with the help of linking conjunctions and comparative constructions:

(7) "Like an old soul in a small body» [13]

Epithets are used for expressiveness, to distinguish specific properties of the object. The vast majority of epithets are adjectives, less often adverbs, nouns and others, in most cases it is more than one word, a complete expression: mind-boggling areas, incredible women, a great reader, magnificent women, pretty phenomenal men, etc.

Hyperbole is aimed at enhancing the emotional or evaluation spectrum of a word, exaggerating reality [14]:

(8) «The human spirit can survive anything» [15]

Lexical repetitions play a significant role, they show speaker's attitude to a certain situation. This technique helps to focus the main thought of the host, approving or disapproving of his actions:

(9) «You all had hits, you all had so many hits» [9]

Incomplete sentences play a special role in Oprah's interview. Their task is a quick emotional reaction and an assessment of the statement of the interlocutor: Beautiful! or So critical, etc. Besides, Oprah Winfrey regularly switches to a colloquial layer of the vocabulary. She wants to be closer to the audience and speak its language. Therefore, Oprah uses contractions such as: gonna, wanna, gotta, cuz, etc. It makes her speech real and alive, helps achieve the goal and be understood by any viewer. 
As for fixed expressions, including phraseological units, idioms and others, Oprah also uses them for more expressive speech:

(10) «We only pay lip service to what we really think of children in this country» [16] With the help of fixed expression "pay lip service», Oprah expresses and summarizes the problem of child abuse in America [17].

The repetition of personal pronouns in the speech seems to show the TV presenter's respect for the audience: we all know, we all see, we are all here, let us know, etc. She remembers her target audience and knows that the love of the audience has made her so popular.

Summarizing the above mentioned, the TV presenter does not use standard phrases, her speech is diverse and abounds in such lexical expressive means as: simile, metaphor, metonymy, epithets, hyperbole, colloquial vocabulary, set expressions, etc.

Due to the fact that the format of TV talk show represents mainly an interview, the vast majority of the time the presenter asks questions - specific and direct questions and expects the same specific answers. Before starting an interview, Oprah makes a kind of an introductory lead-in, shares her opinion, expresses her emotions, mentions some facts from the life of the invited guest giving him time to get used to the atmosphere. With the help of this technique, she launches the thought process of the interlocutor, allowing him to prepare an answer, sets the tone and mood, thereby winning the interlocutor over:

(11) «When I look at those tapes of you, and heaven knows, putting this together I think I've seen every piece of video ever done of you, and watching those tapes when, especially in the younger years, you seem to really come alive on stage. Were you as happy off stage as you appear to be on stage?» [9]

Rhetorical questions are used not to obtain a specific answer, but to provoke a reaction:

(12) «Who wouldn't have wanted that life?» [9]

General questions help the to clarify any facts or topic of discussion:

(13) «Do you still have a place inside you for gratefulness?» [15]

Alternative questions provide the guest with a choice, and also show that Oprah seeks to predict the guest's feelings, accurately catch their mood:

(14) «So do you regret to tape or in a way are you grateful for that experience?» [18] Oprah often asks questions just to show she is thoroughly enlightened on the subject. Using polysyndeton, she gives a certain rhythm to her speech, repeating conjunctions in a certain sequence:

(15) «They're part of the world of tech and politics and business» [18]

Parallel constructions are also found in the analyzed conversations. They are used to focus attention on a certain thought:

(16) «Excellence is the best deterrent to racism, excellence is the best deterrent to sexism» [19]

Analyzing Oprah Winfrey's speech, the following structures and devices were found: anaphora, parenthetical words and constructions, synonyms, homogenous members (in order to convey the meaning of the statement as accurately as possible [20]), periphrases and antitheses.

However, Oprah conducts a dialogue not only with people being interviewed, but also with the audience. At the language level, this is realized through imperative sentences:

(17) «Try to imagine what it would be like for a small child to be locked inside a closet, very much like this one» [21]

At the same time the use of imperative sentences addressed to the interviewee is a call to be frank and honest:

(18) «Tell me this» [18]

Based on the above, the use of effective expressive means, stylistic devices, tactics and communication techniques can help in transmitting information in an accurate and a 
concise manner. Moreover, it enables the recipient to receive the message as intended. Various communication strategies can increase the effectiveness of the process of communication making the spoken utterance more powerful.

\section{Conclusion}

Talk show is a genre of conversational television shows dedicated to various topics for discussion. A distinctive feature is the presence of the host, a guest and the audience in the studio. The atmosphere is often warm, relaxed and welcoming.

Language modelling is the segmentation of lingual units by hierarchical levels. These levels are represented by items ranked according to their importance. First, the sentences are distinguished. Further, the words that are divided into morphemes, which, subsequently, are divided into phonemes. That is, we are talking about syntactic, lexical and phonological levels. The highest level of language structure is syntactic, and the lowest is phonological. We examined the features of speech behaviour of the TV presenter of the American talk show Oprah Winfrey. As a basis of the research, the following steps have been taken: the collection of material and its distribution by language levels (phonetic, lexical, syntactic); analysis of lexical features of speech; analysis of phonetic features of speech. Oprah Winfrey is an American TV presenter, actress, producer, and the most influential woman in America.

Phonetic features of Oprah Winfrey's speech behaviour play an important role in creating an integral image of the speech text, in expressing its thematic development. Phonetic expressive means include intonation, rhythm and rhyme, sound symbolism [22], alliteration, assonance, euphony. Alliteration gives the statement not only special sound, but also intonational expressiveness, with the help of which the TV presenter keeps the attention of her audience, and clearly emphasizes her statements. Through intonation Oprah conveys the meaning of the sentence, expresses her feelings, wishes, etc.

A large set of lexical expressive means makes Oprah's speech behaviour unique and distinguishable. In Oprah's speech, metaphor is almost the most common and effective trope. The metaphors used by Oprah Winfrey are often spontaneous, contain bright images, easily correlated by the viewer with modern realities.

With the help of metonymy, Oprah gives imagination to her statements. Epithets are used to distinguish specific properties of the people, objects or the events. Hyperbole is aimed at enhancing the emotional or evaluation spectrum of a word, exaggerating reality. With the help of allusion, Oprah brings the listener back to certain memories. Irony is also used to create a humorous effect to defuse the situation [23]. Also, lexical repetitions and elliptical sentences express her quick emotional reaction to the assessment of interlocutor's statement. Often, the TV presenter uses colloquial speech and fixed expressions - these techniques make her speech real and lively. The use of personal pronouns shows Oprah's respect for the audience.

To conclude, Oprah Winfrey has her own features of communication with studio guests, but, nevertheless, she selects communicative strategies and tactics individually for each person. She uses lexical means of appraising and evaluative nature to establish contact with the interlocutor; emphasizes the significance and independence of the invited person calling him or her by name.

On the base of thorough analysis of Oprah Winfrey's speech behaviour, she can be attributed to the "leader-thinker" since she likes to think aloud, her speech is rich in expressive means with figurative meaning, she almost does not resort to quotes and clichés. That makes her speech sophisticated and eloquent and worth investigating as the conducted research contributes to the development of a methodology for diagnosing personal qualities 
of a speaker by his speech behaviour as well as to the theory of studying stereotypical speech behaviour of different professional groups.

\section{References}

1. N. Boeva-Omelechko, M. Zheltukhina, O. Ryabko, G. Matveeva, E. Murugova, I. Zyubina, Space and Culture, India, 6(4), 112-121 (2018), doi.org/10.20896/saci.v6i4.387

2. G. Matveeva, I. Zyubina, The Speech Portrait of a Text Sender: Pragmalinguistic Aspect 'Language and Speech in Synchrony and Diachrony, in Proceedings of International Linguistics Conference, Cambridge Scholars Publishing, (2017), http://www.cambridgescholars.com/download/sample/63958

3. C. Emmott, A.J. Sanford, L.I. Morrow, Sentence Fragmentation: Stylistic Aspects, Encyclopedia of Language \& Linguistics (Second Edition), 241-251 (2006), doi.org/10.1016/B0-08-044854-2/04877-X

4. K. Lofton, Oprah: The Gospel of an Icon, Women's Studies International Forum, 34(5), 476-477 (2011), doi.org/10.1016/j.wsif.2011.06.001Get rights and content

5. E. Murugova, G. Matveeva, G. Myasischev, SHS Web of Conferences, 69, 00074 (2019), doi: https://doi.org/10.1051/shsconf/20196900074

6. G. Matveeva, G. Myasischev, O. Gaibaryan, E. Shirina, E3S Web of Conferences, 210 $16011 \quad$ (2020), URL: https://www.e3sconferences.org/articles/e3sconf/pdf/2020/70/e3sconf_itse2020_16011.pdf

7. T. A. van Dijk, Principles of Critical Discourse Analysis, Discourse and Society, 4, 249-283 (1993) doi.org/10.1177/0957926593004002006

8. I. Zyubina, A. Dzyubenko, G. Matveeva, K. Ostrovskaya, A. Ratokhina, New approach to diagnosis of personality traits in psychology, in Proceedings of 3rd International Multidisciplinary Scientific Conference on Social Sciences and Arts SGEM 2016, 24 - 31 August, $2016 \quad$ (2016), DOI: 10.5593/SGEMSOCIAL2016/B11/S01.032.

9. M. Jackson, interview | The Oprah Winfrey Show, 14.03.2020. Available at: https://www.youtube.com/watch? $=$ =VFVm_3QJrEQ\&t=3s

10. A. Nikolaeva, Procedia - Social and Behavioral Sciences, 158, 12-17 (2014), doi.org/10.1016/j.sbspro.2014.12.025

11. N.R. Norrick, Journal of Pragmatics, 42(2), 525-543 (2010), doi.org/10.1016/j.pragma.2009.07.002

12. G. Steen, Metaphor: Stylistic Approaches, Encyclopedia of Language \& Linguistics (Second Edition), 51-57 (2006), doi.org/10.1016/B0-08-044854-2/00525-3

13. An On-Air Intervention with a 17-Year-Old Meth Addict $\mid$ The Oprah Winfrey Show, 08.02.2020. Available at: https://www.youtube.com/watch?v=TB0eDXHSEHs

14. M. Burke, Emotion: Stylistic Approaches, Encyclopedia of Language \& Linguistics (Second Edition), 127-129 (2006), doi.org/10.1016/B0-08-044854-2/00508-3

15. G. Zukav on What to Do When Life Seems Unfair| The Oprah Winfrey Show, 12.02.2020. Available at: https://youtu.be/5ylUZvosaDI

16. Born in the Wrong Body | The Oprah Winfrey Show, 13.01.2020. Available at: https://www.youtube.com/watch?v=eHrThsaCiGw\&feature=emb_logo

17. D. Epstein, D. L. Steinberg, Women's Studies International Forum, 21(1), 77-94 (1998), https://doi.org/10.1016/S0277-5395(97)00079-4 
18. K. Kardashian on Her Relationship with Kanye West | Oprah's Next Chapter, 25.03.2020. Available at: https://www.youtube.com/watch?v=5i6MCjDIKSE

19. Auschwitz with Nobel Laureate and Holocaust Survivor Elie Wiesel| The Oprah Winfrey Show, 17.02.2020. Available at: https://www.youtube.com/watch?v=Igjj870VMts

20. G. Lauerbach, Journal of Pragmatics, 38, 196-215 (2006)

21. C. Moss, A boy who was chained up and tortured by his own family | The Oprah Winfrey Show, 27.03.2020. Available at: https://www.youtube.com/watch?v=3BDsYlt-fug

22. M. Stubbe, J. Holmes, Language \& Communication, 15(1), 63-88 (1995), doi.org/10.1016/0271-5309(94)00016-6

23. J. Boutonnet, Irony: Stylistic Approaches, Encyclopedia of Language \& Linguistics (Second Edition), 28-31 (2006), doi.org/10.1016/B0-08-044854-2/00520-4 